where small effects can none the less reach statistical significance. We note that prior research has generally supported the validity of the EEA in regard to most psychiatric disorders (Kendler \& Gardener, 1998), although bulimia is a possible exception (Hettema et al, 1995; Kendler \& Gardener, 1998). Thus, we re-analysed our data to determine whether the EEA measures of childhood treatment and similitude materially altered our results. The approach is described more fully elsewhere (Hettema et al, 1995); briefly, when we fit statistical models to the trait of a history of lifetime vomiting that included additive genetic, specific common environmental (childhood treatment or similitude), residual common environmental, and individual-specific environmental effects, AE models again provided the best fit to the data. Moreover, heritability estimates from the full models were similar to those reported in our manuscript.

Hence, rather than considering the EEA as an 'all-or-nothing' rule as Curtis implies, our analyses indicate that even if the EEA were violated with respect to vomiting, its impact was evidently small and insufficient to alter either our results or our conclusions.

Bushnell, J. A., Wells, J. E., Hornblow, A. R., et al (1990) Prevalence of three bulimia syndromes in the general population. Psychological Medicine, 20, 671-680.

Hettema, J. M., Neale, M. C. \& Kendler, K. S. (1995) Physical similarity and the equal-environment assumption in twin studies of psychiatric disorders. Behavior Genetics, 25, 327-335.

Kendiler, K. S., MacLean, C., Neale, M., et of (1991) The genetic epidemiology of bulimia nervosa. Americon journal of Psychiatry. 148, 1627-1637.

- Gardener, C. O. (1998) Twin studies of adult psychiatric and substance dependence disorders: are they biased by differences in the environmental experiences of mono- and dizygotic twins in childhood and adolescence? Psychological Medicine, 28, 625-633.

Soundy, T. J., Lucas, A. R., Suman, V. J., et al (1995) Bulimia nervosa in Rochester, Minnesota from 1980 to 1990. Psychological Medicine, 25, 1065-1071.

Sullivan, P. F., Bulik, C. M. \& Kendier, K. S. (1998) Genetic epidemiology of binging and vomiting. British Journol of Psychiatry, 173, 75-79.

P. Sullivan Department of Psychiatry, Virginia Institute for Psychiatric and Behavioral Genetics, PO Box 980126, Richmond, VA 23298-0126, USA

\section{Reserpine exhumed}

Sir: The editorial on reserpine by Healy $\&$ Savage (1998) was provocative and interesting but appeared to be needlessly offensive in one minor respect. When questioning the ability of physicians to correctly diagnose depression, the authors note that the opinions of physician authors from Geelong and Otago need to be interpreted with caution. Why are the physicians from these two large regional towns in Australia and New Zealand singled out in this way when the physician authors of other similar reports are not? Are Healy and Savage implying that physicians in regional antipodean towns in the mid-1950s were in some way less competent than those in Britain and North America? If so, I doubt whether they can adduce any evidence that this was the case. I think the authors should withdraw these comments or inform us of the reason why these two towns were singled out for mention in their article.

Hoaly, D. \& Savase, M. (1998) Reserpine exhumed. British journal of Psychiatry. 172. 376-378.

D. Ames Academic Unit for the Psychiatry of Old Age, North West Hospital Psychogeriatric Service, Department of Psychiatry, Royal Park Hospital, Private Bag No 3 PO Parkville, Victoria 3052. Australia

Author's reply: The particular mention of authors from Geelong and Otago (Healy \& Savage, 1998) stemmed from the fact that these were the authors of the two articles that immediately preceded the randomised trial of reserpine in depressive disorders conducted by Davies \& Shepherd (1955). On two facing pages of this article you can see an article by Wallace from Geelong and the first page of the Shepherd trial. For anyone sensitive to defining moments in history this conjunction has considerable resonance. The authors of these pieces, therefore, were clearly the ones to focus on in order to bring out this aspect of the story. We took considerable care, however, to research the background of Dr Wallace, in particular, and to know a good deal about this career. In brief, he was a physician who appears to have been well esteemed by his colleagues but he was not one who appears to have had a particular interest in mainstream adult psychiatry at the time he wrote his report and did not develop one subsequently. In contrast, some of the other physicians referred to noted not only reserpine's capacity to cause distress but also its potential usefulness for the treatment of depression.
Healy, D. \& Savage, M. (1998) Reserpine exhumed. British journal of Psychiotry, IT2, 376-378.

Davies, D. L. S Shepherd, M. (1995) Reserpine in the treatment of anxious and depressed patients. Lancet, $i$, $117-121$.

D. Healy North Wales Department of Psychological Medicine, Hergest Unit, Bangor, Gwynedd LL57 2PW

\section{Clozapine-induced extrinsic allergic alveolitis}

Sir: The following case highlights potentially life-threatening cardio-respiratory complications of clozapine. A 45-year-old male with schizophrenia, with a medical background of heavy smoking and asymptomatic right ventricular hypertrophy, had an uneventful commencement of clozapine. Fifteen days into treatment, on $200 \mathrm{mg}$ twice daily, he presented with lethargy and pyrexia. Additional findings included: a leucocytosis with eosinophilia, elevated erythrocyte sedimentation rate (90) and irregular tachycardia/creatine kinase (124). Clinical examination was essentially unremarkable: clear chest, no increase in venous pressure, normal range blood pressure, no pericardial rub, no chest discomfort. However, malodorous smell and incontinence of urine were noted.

Despite a five-day course of antibiotics treatment for a presumed urinary tract infection, the pyrexia persisted, and additional symptoms appeared; non-productive cough and external dyspnoea.

The chest $\mathrm{X}$-ray after commencement of clozapine revealed striking changes from the pre-clozapine X-ray, widespread abnormal markings in both lungs, which were reticular and linear were shown. There were also extensive septal lines in the periphery of the lung and a fairly dense perihilar haze. The appearances were suggestive of an acute inflammatory process. A computerised tomography scan showed small bilateral pleural effusions with widespread non-specific interstitial shadowing, having the appearance of a drug-induced reaction. Clinically, an elevated venous pressure and a gallop rhythm were noted. There was no demonstrated 'wheeze' or 'stridor'. Despite the advanced radiological and examination findings, the patient appeared surprisingly well. A diagnosis of extrinsic allergic alveolitis was made and the clozapine was discontinued. 